\title{
Effects of Semi-solid Isothermal Heat Treatment on Microstructures and Damping Capacities of Fly Ash Cenosphere/AZ91D Composites
}

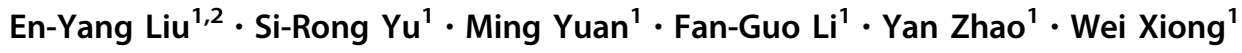

Received: 8 December 2017 / Revised: 26 January 2018/Published online: 9 April 2018

(C) The Chinese Society for Metals and Springer-Verlag GmbH Germany, part of Springer Nature 2018

\begin{abstract}
The fly ash cenosphere/AZ91D composites were successfully prepared and isothermally heat-treated at different temperatures for different time. The effects of semi-solid isothermal heat treatment on the microstructures and damping capacities of fly ash cenosphere/AZ91D composites were investigated. With the increase in isothermal temperature or holding time, the small liquid droplets within grains increased in size but decreased in quantity. The average size and shape factor of $\mathrm{Mg}_{2} \mathrm{Si}$ particles increased with the rise of isothermal temperature. The damping capacities of the composites were improved by isothermal heat treatment. At room temperature, the composites after heat treatment at 520 and $550{ }^{\circ} \mathrm{C}$ had a higher damping capacity due to interface damping when the strain amplitude was lower than about $8.8 \times 10^{-5}$, and the composite after heat treatment at $580^{\circ} \mathrm{C}$ had a better damping capacity because of the dislocation damping under the condition of high strain amplitude. The damping capacities of the composites increased with the rise of the test temperature, and the damping mechanisms varied depending on different test temperatures. The interface damping played an important role when the test temperature was below about $100{ }^{\circ} \mathrm{C}$, and the dislocation damping and grain boundary damping took effect with the rise of test temperature.
\end{abstract}

Keywords Fly ash cenosphere $\cdot$ Magnesium matrix composite $\cdot$ Semi-solid isothermal heat treatment $\cdot$ Microstructural evolution · Damping capacity

\section{Introduction}

As the lightest metallic structural materials, magnesium alloys have many advantages such as high specific strength and stiffness, high damping capacity, good electromagnetic shielding effectiveness, convenient recyclability and so on $[1,2]$. They play a significant role in reducing the weight of vehicles, cutting down energy consumption and environmental pollution. However, compared with other structural materials, the strength of magnesium alloys is still low,

Available online at http://link.springer.com/journal/40195

En-Yang Liu

ley@upc.edu.cn

1 College of Mechanical and Electrical Engineering, China University of Petroleum (East China), Qingdao 266580, China

2 Key Laboratory of Oil and Gas Equipment of Education Ministry, Southwest Petroleum University, Chengdu 610500, China which limits their applications [3]. Magnesium matrix composites, usually possessing higher mechanical properties and damping capacities, are becoming competitive materials in electronics, automotive, aerospace and other industries $[4,5]$.

Fly ash, an industrial by-product of coal combustion in thermal power plants, is available in large quantities all over the world. If not properly disposed of, it can cause environmental pollution. Nowadays, fly ash is mainly used in the construction industry, such as the manufacture of refractories, cement and concrete, etc. [6, 7]. In agriculture, fly ash can buffer the soil $\mathrm{pH}$, improve the soil texture and aeration, and reduce soil bulk density, making it a low-cost amendment for soils [8]. In addition, fly ash can also be used as a catalyst for various reactions, as an adsorbent to remove gases and metal ions, and in the recovery of valuable metals [9-11]. Despite these applications, the utilization rate of fly ash has been estimated to be about $45 \%$ [12]. Therefore, a great deal of fly ash has yet been left untreated and more recycling methods need to be developed. 
Depending on the density, fly ash can be classified into two types, precipitator and cenosphere. Fly ash precipitators, with density greater than $1.0 \mathrm{~g} / \mathrm{cm}^{3}$, are solid or thickwall spherical particles of fly ash. Fly ash cenospheres (FAC), which have a density in the range $0.4-1.0 \mathrm{~g} / \mathrm{cm}^{3}$, are hollow thin-wall particles of fly ash [13]. Recently, low-cost, light FAC-reinforced metal matrix composites have been developed, which provides a new idea for the recovery and utilization of fly ash [14-16]. The use of FAC in magnesium matrix composites offers the advantage of improving certain properties of the composites, and reducing the amount of fly ash by a high value-added method. Rohatgi et al. [17] prepared FAC/AZ91D composites by die casting technique and discussed the effects of FAC additions on the microstructure and mechanical properties of the composites. The results show that the addition of FAC causes microstructure refinement of the matrix, and the dendrite size decreases with the increase in FAC content. The tensile strength and hardness of the composites increase with the rise of FAC content. However, compared with AZ91D magnesium alloy, the composite with 5 wt.\% FAC exhibits a lower compressive strength. Two kinds of reinforcements, raw FAC and $\mathrm{Ca}(\mathrm{OH})_{2}$ modified FAC, were used to fabricate magnesium matrix composites by $\mathrm{Lu}$ et al. [18]. Then, the electromagnetic interference shielding effectiveness (EMI SE) of the composites was studied. The results show that the modified FAC improves the EMI SE of the matrix obviously. Yu et al. [19] investigated the wear behavior of FAC/AZ91D composites under dry sliding condition, and the results indicate that the wear resistance of the composites is improved by the addition of FAC. Using disintegrated melt deposition technique, Nguyen et al. [20] synthesized light-weight FAC/magnesium composite foams, which exhibited better dimensional stability and significant improvements in mechanical properties.

By comparison with other metal matrix composites, magnesium matrix composites usually exhibit a high damping capacity and a low density. Various reinforcements, such as SiC particles [21], graphite particles [22], silica nanoparticles [23], $\mathrm{Mg}_{2} \mathrm{Si}$ [24] and $\mathrm{TiC}$ [25], were added or in situ formed in magnesium alloys, producing high damping composites. With the development of magnesium matrix composites technology, it is possible to further improve the damping capacities of magnesium matrix composites by heat treatment. Zhang et al. [26] prepared TiC/AZ91 composites by in situ synthesis method and compared the damping capacities of foundry composites and heat-treated composites. The results show that T4 and T6 heat treatment could improve the damping capacities of composites, due to the decrease in activation energy and the elongation of the effective length of movable dislocations in the matrix. Compared with dendritic microstructure, magnesium matrix composites with nondendritic microstructure may have special properties [27, 28]. Semi-solid isothermal heat treatment (SSIT) is a simple way which can be used to produce non-dendritic materials. However, most of the existing investigations have focused on the microstructures of magnesium alloys treated by SSIT [29-31]. Up to now, little study has been carried out for the effect of SSIT on the damping capacities of FAC/AZ91D composites. The objective of the present study is to investigate the microstructure evolution mechanism during SSIT and elucidate the effect of isothermal temperature on the damping capacities of FAC/AZ91D composites.

\section{Materials and Experimental Procedure}

\subsection{Materials}

AZ91D magnesium alloy and FAC were used as raw materials in this study. AZ91D magnesium alloy was provided by Wenxi Yinguang Magnesium Industry Group, China. Table 1 shows the chemical composition of AZ91D magnesium alloy. The FAC were collected from a thermal power plant in Hebei Province, China. The received FAC were pretreated before use. The FAC of different particle sizes were first screened with a sieve, and only the FAC with the average diameter of $124 \mu \mathrm{m}$ were used. The screened FAC were firstly washed by 5 wt.\% $\mathrm{NaOH}$ solution, and then by distilled water. Finally, they were dried at $80{ }^{\circ} \mathrm{C}$ in air. The morphology of pretreated FAC was observed by a JXA-8230 electron probe microanalyzer (EPMA), and the chemical composition was analyzed by an energy-dispersive spectrometer (EDS). As shown in Fig. 1, the main elements detected by EDS are silicon, oxygen, aluminum, and small amounts of potassium, calcium, magnesium, iron and sodium. Combined with the previous literature, it can be estimated that the major components of FAC are silica and alumina [32, 33].

\subsection{Preparation of FAC/AZ91D Composites}

The FAC/AZ91D composite was prepared by stir casting method. The steel crucible was placed in an electric resistance furnace and preheated to $200{ }^{\circ} \mathrm{C}$. Then, $800 \mathrm{~g}$ of AZ91D magnesium alloy was placed in the crucible and heated to $720{ }^{\circ} \mathrm{C}$. When the magnesium alloy was completely melted, the temperature of the melt was cooled to $590{ }^{\circ} \mathrm{C}$. After that, $51.06 \mathrm{~g}$ of FAC preheated to $200{ }^{\circ} \mathrm{C}$ was added to the melt, and the slurry was stirred for $3 \mathrm{~min}$ at a rotation speed of $675 \mathrm{r} / \mathrm{min}$ to get the uniform distribution of FAC in the melt. Then, the slurry was rapidly reheated to $720{ }^{\circ} \mathrm{C}$, stirred for $1 \mathrm{~min}$, and poured into a 
Table 1 Chemical composition of AZ91D magnesium alloy

\begin{tabular}{lllllllll}
\hline Element & $\mathrm{Al}$ & $\mathrm{Zn}$ & $\mathrm{Mn}$ & $\mathrm{Si}$ & $\mathrm{Cu}$ & $\mathrm{Fe}$ & $\mathrm{Ni}$ & $\mathrm{Mg}$ \\
\hline Mass fraction (\%) & 9.03 & 0.66 & 0.20 & 0.038 & 0.0016 & 0.0026 & 0.00078 & Bal. \\
\hline
\end{tabular}

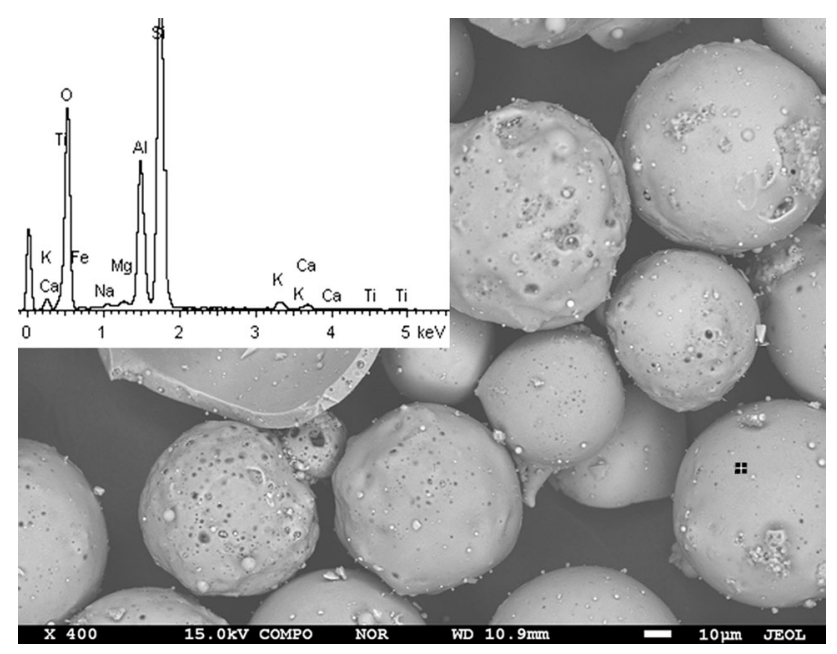

Fig. 1 Morphology of pretreated FAC and EDS result

graphite mold, forming a cylindrical ingot with FAC content of $6 \mathrm{wt} . \%$. During the fabrication process, $3 \mathrm{vol} . \%$ $\mathrm{SF}_{6}+\mathrm{CO}_{2}$ protective gas was used to prevent the oxidation and combustion of magnesium alloy. The facility used to prepare the FAC/AZ91D composite is schematically shown in Fig. 2.

\subsection{Semi-solid Isothermal Heat Treatment}

The isothermal heat treatment was carried out in a heating resistance furnace, with 3 vol. $\% \mathrm{SF}_{6}+\mathrm{CO}_{2}$ used as protective gas. The FAC/AZ91D composite ingots were heated from room temperature to different temperatures:

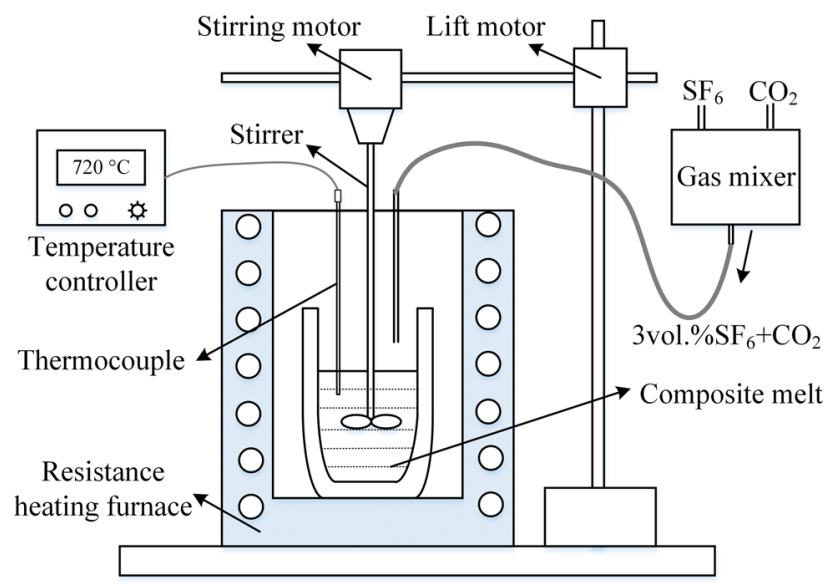

Fig. 2 Schematic diagram of the facility used to prepare FAC/AZ91D composite
520, 550, 570, and $580{ }^{\circ} \mathrm{C}$, then isothermally held for different time. After that, they were quenching in water.

\subsection{Characterization Techniques}

Differential thermal analysis (DTA) heating curve of ascast FAC/AZ91D composite was measured by an SII TG/ DTA 6300 differential thermal analyzer. Specimens with a weight of 7-10 $\mathrm{mg}$ were placed in an alumina crucible and heated to $640{ }^{\circ} \mathrm{C}$ with a heating rate of $8{ }^{\circ} \mathrm{C} / \mathrm{min}$. Analyses were carried out with argon as the furnace atmosphere, and the flow rate was $100 \mathrm{ml} / \mathrm{min}$.

Phases in the composites were identified by X-ray diffraction (XRD, X'Pert Pro MPD, PANalytical Company) using $\mathrm{Cu} K_{\alpha}$ radiation. Specimens for microstructure investigations were cut from the as-cast composite and heat-treated composites, respectively, and then polished. After being etched by 5 wt.\% oxalic acid solution, microstructure observation was carried out using an optical microscope (OM, Nikon Epiphot-300). The particle size $\left(D=(4 A / \pi)^{1 / 2}\right.$, where $A$ is the area of the particle) and shape factor $\left(F=4 \pi A / P^{2}\right.$, where $P$ is the particle perimeter) were measured by the Image-Pro Plus software.

The damping capacities of the composites were measured by a dynamic mechanical analyzer (DMA, TA Q800) with dual cantilever vibration mode. The dimensions of the specimens were $60 \mathrm{~mm} \times 6 \mathrm{~mm} \times 1 \mathrm{~mm}$. For the measurements of strain amplitude dependent damping capacities, the test conditions were as follows: the strain amplitude ranged from $1 \times 10^{-6}$ to $1 \times 10^{-4}$, the vibration frequency was $1.0 \mathrm{~Hz}$, and the test temperature was room temperature. For the measurement of temperaturedependent damping capacities, the test conditions were as follows: the strain amplitude was $1 \times 10^{-5}$, the vibration frequency was $1.0 \mathrm{~Hz}$, the temperature range was from room temperature to $320^{\circ} \mathrm{C}$, and the heating rate was $5{ }^{\circ} \mathrm{C} /$ min. The damping capacity was evaluated by the loss tangent $(\tan \varphi)$, where $\varphi$ was the lag angle between the strain and the stress.

\section{Results and Discussion}

\subsection{Differential Thermal Analysis}

The DTA heating curve of as-cast FAC/AZ91D composite is shown in Fig. 3. Two endothermic peaks appear on the DTA curve. The first endothermic peak is at about 


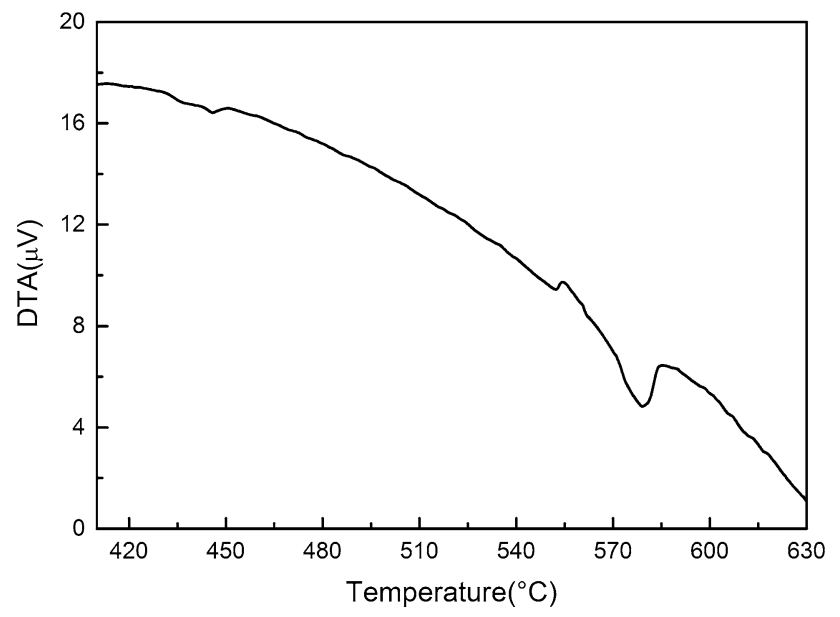

Fig. 3 DTA heating curve of the as-cast FAC/AZ91D composite

438-446 ${ }^{\circ} \mathrm{C}$, mainly due to the phase transformation of $\beta$ $\mathrm{Mg}_{17} \mathrm{Al}_{12}$. The second endothermic peak ranges from 561 to $584{ }^{\circ} \mathrm{C}$, due to the fact that the melting of $\alpha-\mathrm{Mg}$ grains requires a large amount of heat. Therefore, the isothermal temperatures from 520 to $580{ }^{\circ} \mathrm{C}$ were selected for the isothermal heat treatment of the composites.

\subsection{Microstructure of the As-cast Composite}

The XRD patterns of AZ91D alloy and FAC/AZ91D composite are presented in Fig. 4. As can be seen, the AZ91D alloy is composed of $\alpha-\mathrm{Mg}$ and $\beta-\mathrm{Mg}_{17} \mathrm{Al}_{12}$. In addition to these phases, $\mathrm{Mg}_{2} \mathrm{Si}$ and $\mathrm{MgO}$ are also found in the composite. Earlier report has shown that the FAC can react with the magnesium alloy in the preparation process of the composite, resulting in the formation of $\mathrm{Mg}_{2} \mathrm{Si}$ and $\mathrm{MgO}$ [34]. The microstructure of as-cast FAC/AZ91D composite is shown in Fig. 5. It can be seen that the FAC

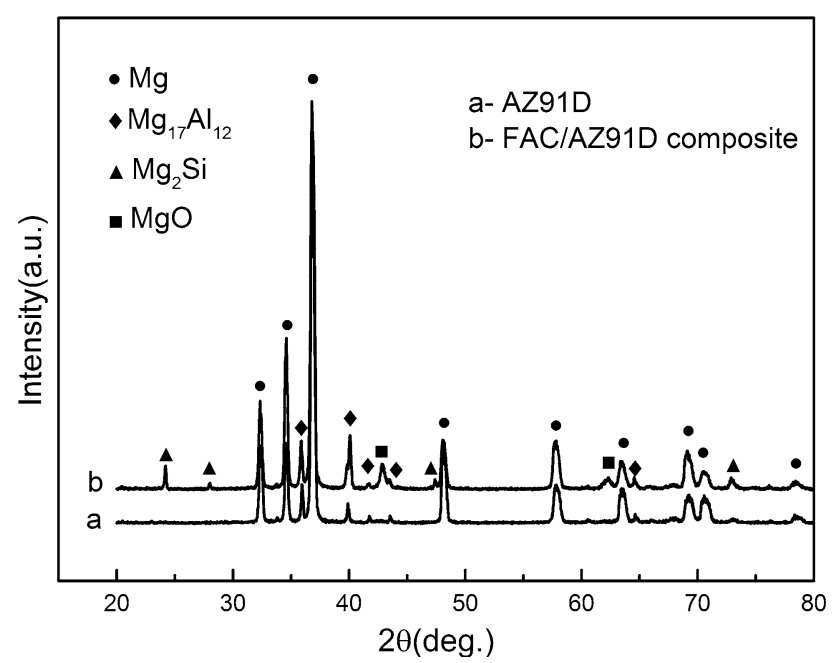

Fig. 4 XRD patterns of AZ91D alloy and FAC/AZ91D composite are relatively uniformly distributed in the matrix and filled in magnesium alloy matrix due to the reaction with the molten alloy. A small number of FAC are broken during the preparation process of the composite. The $\beta-\mathrm{Mg}_{17} \mathrm{Al}_{12}$ phases are distributed along the grain boundaries and a small amount of them is found inside the $\alpha-\mathrm{Mg}$ grains. Under larger magnification, the $\beta-\mathrm{Mg}_{17} \mathrm{Al}_{12}$ phase consists of eutectic $\beta-\mathrm{Mg}_{17} \mathrm{Al}_{12}$ and precipitate $\beta-\mathrm{Mg}_{17} \mathrm{Al}_{12}$, as shown in Fig. 5b. Moreover, polygonal $\mathrm{Mg}_{2} \mathrm{Si}$ particles are also found in the matrix. However, as the content of $\mathrm{MgO}$ in the composite is very low, it cannot be found in Fig. 5.

\subsection{Semi-solid Microstructure Evolution}

\subsubsection{Effect of Isothermal Temperature on Semi-solid Microstructure}

Figure 6 shows the microstructural evolution of FAC/ AZ91D composites after isothermal heat treatment at different temperatures for $40 \mathrm{~min}$. As shown in Fig. 6a, after isothermal holding at $520{ }^{\circ} \mathrm{C}$ for $40 \mathrm{~min}$, the eutectic and precipitate $\beta-\mathrm{Mg}_{17} \mathrm{Al}_{12}$ disappeared, and a lot of "entrapped liquid droplets" were found in the matrix. This is related to the presence of alloying elements segregation during the partial re-melting. When the heating temperature rises from the room temperature, the precipitate $\beta$ $\mathrm{Mg}_{17} \mathrm{Al}_{12}$ will be decomposed to form solute atoms and dissolved in the magnesium matrix. As the heating temperature rises to the eutectic temperature, the eutectic structures begin to melt, and liquid droplets are formed at grain boundaries. With the increase in heating temperature, small areas which are rich in aluminum and zinc within grains may start to melt, and tiny liquid droplets are formed inside the grains. After isothermal holding at $550{ }^{\circ} \mathrm{C}$ for $40 \mathrm{~min}$, fine liquid droplets become larger as a result of growth and coalescence, resulting in a decrease in the number of the entrapped liquid droplets. Meanwhile, some liquid droplets at grain boundaries may join together to form discontinuous liquid films, as shown in Fig. 6b. With the increase in isothermal temperature, the amount of liquid phase increases and the liquid film becomes thicker, as shown in Fig. 6c, d. In addition, it is worth noting that these small liquid droplets will rapidly solidify during the subsequent quenching, resulting in "small magnesium alloy particles" in the matrix.

It is worth noting that the morphology of $\mathrm{Mg}_{2} \mathrm{Si}$ particles has also changed significantly during isothermal heat treatment. Figure 7 shows variations of the average size and shape factor of $\mathrm{Mg}_{2} \mathrm{Si}$ particles after isothermal heat treatment at different temperatures for $40 \mathrm{~min}$. It can be found that the average size and shape factor of $\mathrm{Mg}_{2} \mathrm{Si}$ particles increase with the rise of isothermal temperature. Compared with Figs. 5 and 6, it can be seen that the $\mathrm{Mg}_{2} \mathrm{Si}$ 

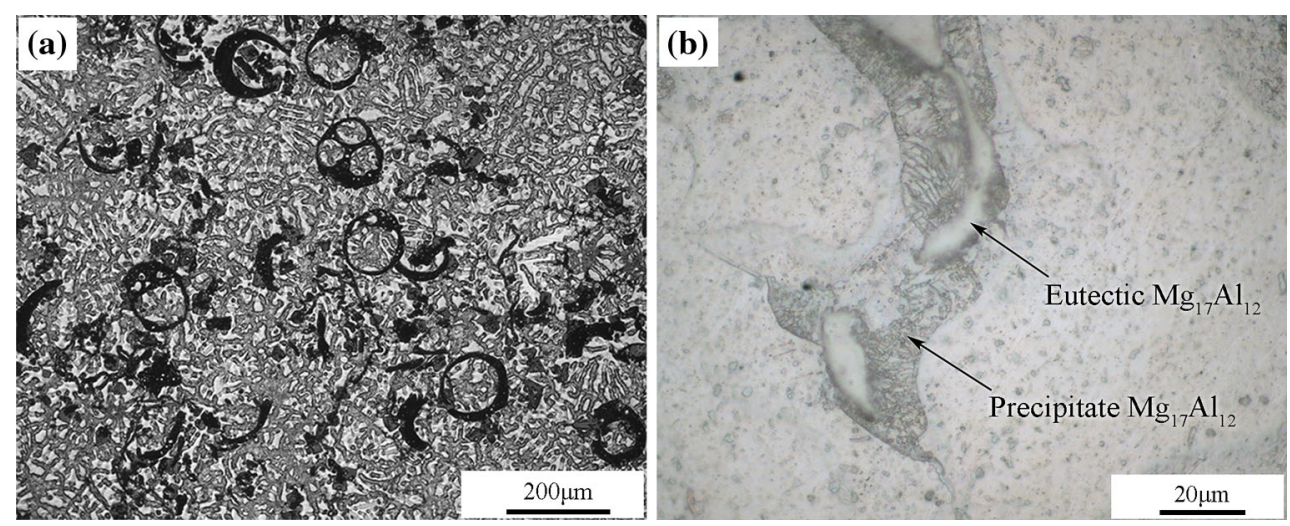

Fig. 5 Microstructure of as-cast FAC/AZ91D composite (a) and a larger magnification of $\mathrm{Mg}_{17} \mathrm{Al}_{12}(\mathbf{b})$
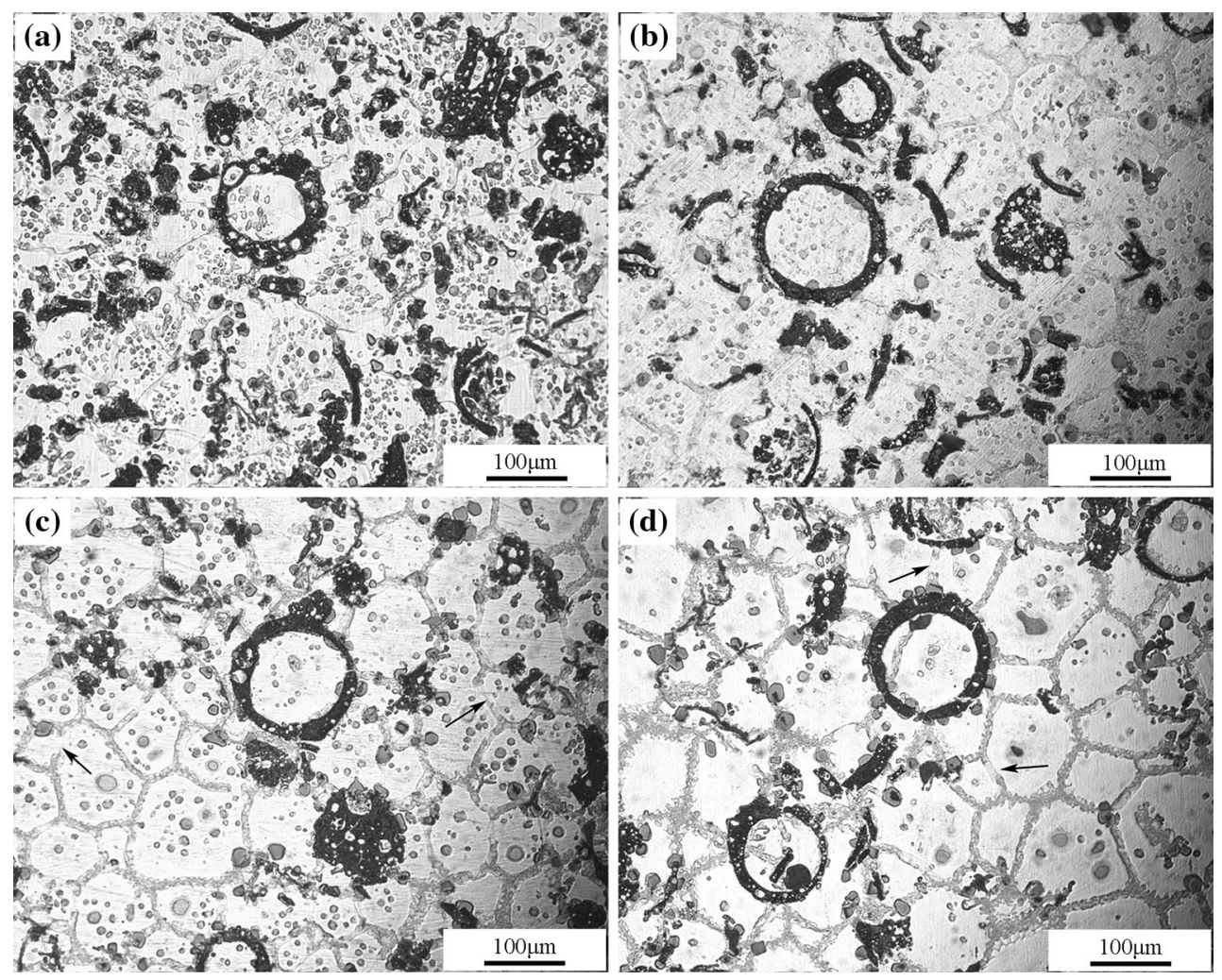

Fig. 6 Semi-solid microstructures of FAC/AZ91D composites after isothermal heat treatment at different temperatures and held for 40 min: a $520{ }^{\circ} \mathrm{C}$, b $550{ }^{\circ} \mathrm{C}$, c $570{ }^{\circ} \mathrm{C}$, d $580{ }^{\circ} \mathrm{C}$

particles are irregularly polygonal in the as-cast state, while they are nearly spherical particles after isothermal heat treatment. According to the Gibbs-Thomson formula, the $\mathrm{Si}$ concentration in the matrix near the $\mathrm{Mg}_{2} \mathrm{Si}$ phase can be expressed as [35]

$C_{\alpha}(r)=C_{\alpha}(\infty) \exp \left(\frac{2 \sigma}{k_{\mathrm{B}} T r}\right)$

where $C_{\alpha}(r)$ is the $\mathrm{Si}$ concentration at the position with a curvature radius $r ; C_{\alpha}(\propto)$ is the $\mathrm{Si}$ concentration at flat interface; $\sigma$ is interfacial energy; $v_{\mathrm{B}}$ is the volume of $\mathrm{Si}$ atom; $k_{\mathrm{B}}$ is the shape-related coefficient, and $T$ is temperature. According to Eq. (1), the Si concentration increases with the decrease in curvature radius. That is to say, for the polygonal $\mathrm{Mg}_{2} \mathrm{Si}$ particles, the Si concentration at the sharp corners is higher than that at the edge positions. Therefore, the $\mathrm{Si}$ atoms would diffuse from the position where the curvature radius is smaller to the position where the curvature radius is larger during isothermal heat treatment. In order to keep the balance of $\mathrm{Si}$ concentration, the $\mathrm{Mg}_{2} \mathrm{Si}$ phase at the position with smaller curvature radius would dissolve, resulting in a larger curvature radius. As a result, 


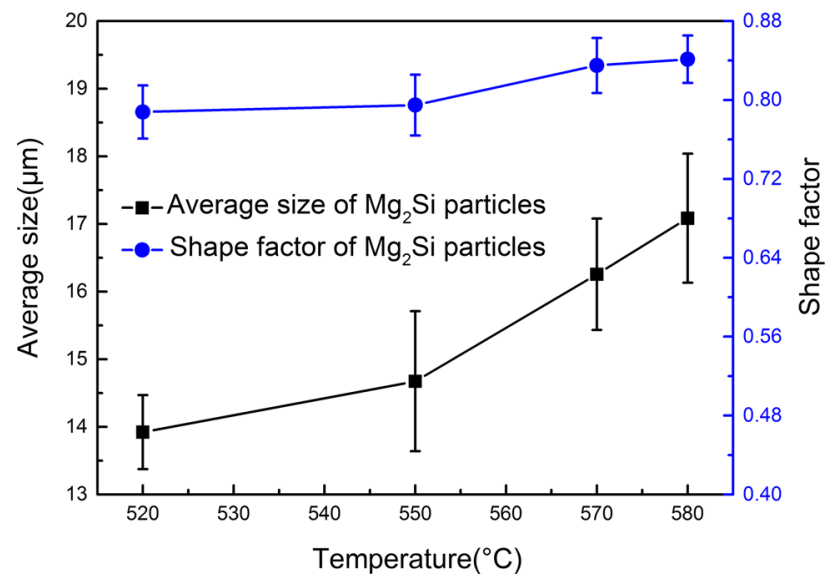

Fig. 7 Variations of the average size and shape factor of $\mathrm{Mg}_{2} \mathrm{Si}$ particles treated at different temperatures for $40 \mathrm{~min}$

the nearly spherical $\mathrm{Mg}_{2} \mathrm{Si}$ particles are formed. With the increase in isothermal temperature, the diffusion velocity of $\mathrm{Si}$ atoms increases, and the shape factor of $\mathrm{Mg}_{2} \mathrm{Si}$ particles becomes larger.

As can be seen from Fig. 7, $\mathrm{Mg}_{2} \mathrm{Si}$ particles are coarsened during isothermal heat treatment. Ostwald ripening mechanism plays a dominant role in the coarsening process. During isothermal heat treatment, the $\mathrm{Si}$ atoms diffused from regions with high curvature to regions with low curvature based on Eq. (1). Then, the small $\mathrm{Mg}_{2} \mathrm{Si}$ particles dissolved, and the large $\mathrm{Mg}_{2} \mathrm{Si}$ particles grew up. The dissolution of small $\mathrm{Mg}_{2} \mathrm{Si}$ particles results in a decrease in the number of $\mathrm{Mg}_{2} \mathrm{Si}$ particles per unit volume and an increase in the average size.

\subsubsection{Effect of Holding Time on Semi-solid Microstructure}

Figure 8 shows the microstructural evolution of $\mathrm{FAC} /$ AZ91D composites after isothermal heat treatment at $570{ }^{\circ} \mathrm{C}$ and held for (a) $50 \mathrm{~min}$, (b) $60 \mathrm{~min}$, and (c) $120 \mathrm{~min}$, respectively. As can be seen from Fig. 8, some liquid pools are formed by the coalescence of the intragranular liquid droplets. With extension of holding time, these liquid pools migrate out of the $\alpha-\mathrm{Mg}$ grains and eventually into the liquid phase by diffusion in order to reduce the solid-liquid interfacial area. In addition, the amount of the liquid phase and the average size of $\alpha-\mathrm{Mg}$ grains increase with the extension of holding time. After isothermal holding for $120 \mathrm{~min}$, globular solid grains are formed, and the volume fraction of the liquid phase exceeds $50 \%$.

As can be seen from Figs. 6 and 8, the semi-solid isothermal heat treatment has little effect on the morphology of FAC. The main reason is that the FAC is mainly composed of silica and alumina, whose melting points are much higher than the isothermal temperature. However, the silica and alumina in the FAC may react with the magnesium as follows [36]:

$$
2 \mathrm{Mg}+\mathrm{SiO}_{2} \rightarrow \mathrm{Si}+2 \mathrm{MgO} \quad \Delta G_{1}^{0}=-76500+15.4 T
$$

$3 \mathrm{Mg}+\mathrm{Al}_{2} \mathrm{O}_{3} \rightarrow 2 \mathrm{Al}+3 \mathrm{MgO} \quad \Delta G_{2}^{0}=-37800+9.3 T$

When the isothermal temperature is in the range of 520 $580{ }^{\circ} \mathrm{C}, \Delta G_{1}^{0}<0, \Delta G_{2}^{0}<0$, indicating the occurrences of reaction (2) and (3). $\mathrm{MgO}$ and $\mathrm{Al}$ can be obtained from the reaction between the magnesium and alumina. $\mathrm{Al}$ atoms diffuse and dissolve in the magnesium matrix at the isothermal temperature, and the supersaturated solid solution of $\alpha-\mathrm{Mg}$ or $\beta-\mathrm{Mg}_{17} \mathrm{Al}_{12}$ phase is formed during the subsequent cooling process. In addition, Si can be obtained from the reaction between the magnesium and silica. Due to the large difference in the atomic radius and the electronegativity between $\mathrm{Mg}$ and $\mathrm{Si}$ atoms, the solid solubility of $\mathrm{Si}$ in magnesium matrix is very small, and the stable compound $\mathrm{Mg}_{2} \mathrm{Si}$ tends to form easily.

\subsubsection{Semi-solid Microstructure Evolution Mechanism}

According to the above discussion mentioned, the microstructural evolution process can be divided into five
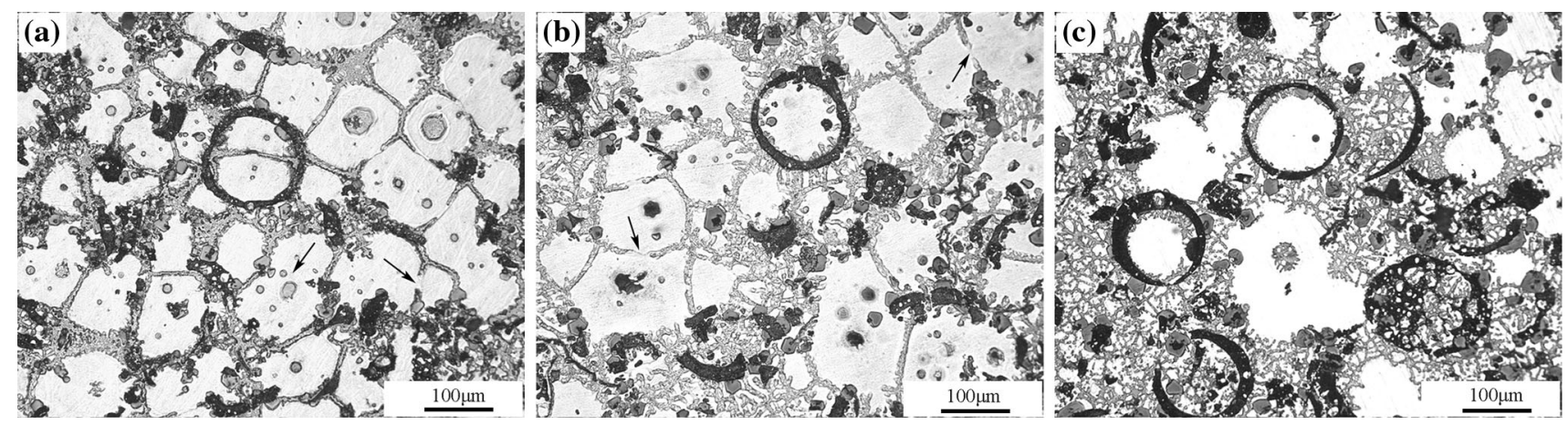

Fig. 8 Semi-solid microstructures of FAC/AZ91D composites after isothermal heat treatment at $570{ }^{\circ} \mathrm{C}$ for a $50 \mathrm{~min}, \mathbf{b} 60 \mathrm{~min}, \mathbf{c} 120 \mathrm{~min}$ 
steps. (I) Initial coarsening of the $\alpha-\mathrm{Mg}$ dendrites, (II) structural separation, (III) coarsening of polygonal $\alpha-\mathrm{Mg}$ grains by the coalescence mechanism, (IV) spheroidization of polygonal solid grains and (V) final coarsening by Ostwald ripening mechanism [37].

In the initial stage of isothermal heat treatment, the precipitate $\beta-\mathrm{Mg}_{17} \mathrm{Al}_{12}$ dissolves in the matrix when the heating temperature is lower than the eutectic temperature, resulting in the coarsening of $\alpha-\mathrm{Mg}$ dendrites through the mergence of their arms. When the heating temperature reaches the eutectic point, the residual $\beta$ phase melts and the liquid phase around $\alpha-\mathrm{Mg}$ grains is formed. As the heating further continues, grain boundaries begin to melt because of the requirement of increasing liquid amount due to the increase in temperature, resulting in the separation of coarsened $\alpha-\mathrm{Mg}$ dendrites by thin liquid films. Then, individual polygonal solid grains are formed, as shown in Fig. 6c.

As the heating proceeds, $\alpha-\mathrm{Mg}$ grains would grow and coarsen. The coarsening process is controlled by two mechanisms, coalescence and Ostwald ripening. When the volume fraction of the liquid is low, the neighboring grains are easily to contact with each other, and the coalescence is the dominant mechanism. In order to reduce the solidliquid interfacial energy, the contacted solid grains would merge by grain rotation or grain boundary migration. As shown in Figs. 6c, d and 8a, b, the arrows in the micrographs refer to the grain boundaries that disappeared because of coalescence of solid grains. Meanwhile, the spheroidization of polygonal solid grains occurs during the growing and coarsening of the microstructure. Since the melting point of the solid phase decreases with the increase in the curvature, the corners of polygonal solid grains would preferentially melt as the heating proceeds, resulting in globular solid grains. When the volume fraction of the liquid is high, the distance between solid grains increases and Ostwald ripening becomes the dominant coarsening mechanism, as shown in Fig. 8c. As a diffusion-controlled process, the Ostwald ripening consists of dissolution and reprecipitation. Since the semi-solid slurry tends to lower its energy by reducing the solid-liquid interfacial area, the large particles would grow at the expense of small ones, resulting in the dissolution of small particles. Moreover, as the coarsening of particles is realized by the diffusion of atoms, the coarsening rate is much lower than that of the coalescence mechanism.

\subsection{Effect of Isothermal Heat Treatment on the Damping Capacities of FAC/AZ91D Composites}

Figure 9 shows the variations of the damping capacities with the strain amplitude measured at room

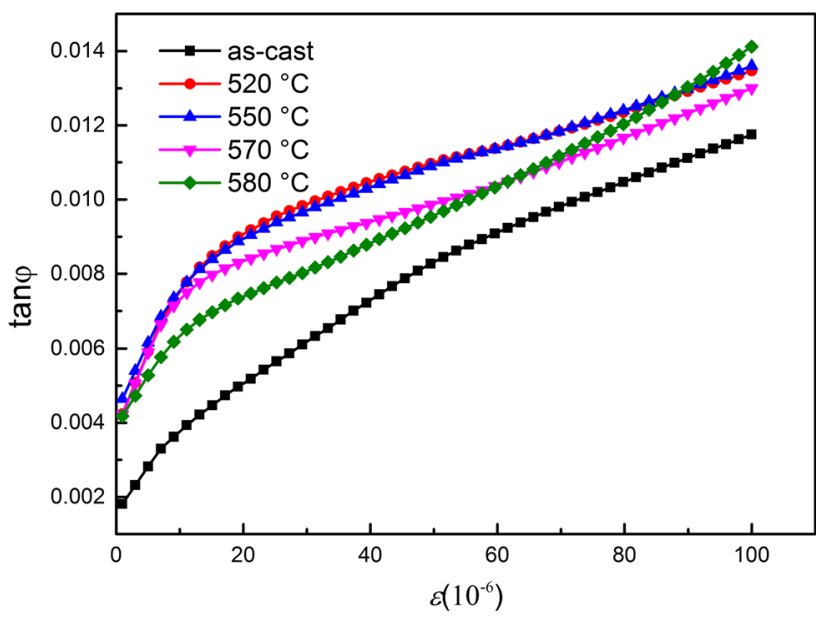

Fig. 9 Variations of the damping capacities with strain amplitude at room temperature of FAC/AZ91D composites after heat treatment at different temperatures for $40 \mathrm{~min}$

temperature of FAC/AZ91D composites after isothermal heat treatment at different temperatures for $40 \mathrm{~min}$. It can be noted that the damping capacities of the composites increase with the increase in strain amplitude, and the damping capacities of the composites after isothermal heat treatment are higher than that of the as-cast composite. When the strain amplitude is lower than about $8.8 \times 10^{-5}$, the composites after heat treatment at 520 and $550{ }^{\circ} \mathrm{C}$ have a better damping capacity. The composite after heat treatment at $580{ }^{\circ} \mathrm{C}$ has a better damping capacity when the strain amplitude is higher than $8.8 \times 10^{-5}$.

According to the Granato-Lücke theory [38, 39], the damping capacity depends on the energy consumed by the dislocation motion. When the strain amplitude is small, the dislocations are pinned by the weak pinning points. The dislocation segments bow out between weak pinning points, which contributes to strain-independent damping $\left(\delta_{0}\right)$. The value of the strain-independent damping $\left(\delta_{0}\right)$ can be expressed as

$\delta_{0} \sim \rho L_{\mathrm{d}}^{4}$

When the breakaway strain is reached, the dislocation segments break away from the weak pinning points but are still pinned by strong points, which causes strain-dependent damping $\left(\delta_{H}\right) . \delta_{H}$ can be expressed as [40]

$\delta_{H}=\frac{C_{1}}{\varepsilon} \exp \left(\frac{-C_{2}}{\varepsilon}\right)$

$C_{1}=\frac{\rho F_{\mathrm{B}} L_{\mathrm{N}}^{3}}{6 b E L_{\mathrm{d}}^{2}}$

$C_{2}=\frac{F_{\mathrm{B}}}{b E L_{\mathrm{d}}}$

where $\rho$ and $L_{\mathrm{d}}$ are the dislocation density and the average 
distance between weak pinning points; $F_{\mathrm{B}}$ is the binding force between dislocations and weak pinning points; $L_{\mathrm{N}}$ is the average distance between strong pinning points; $E$ is the elastic modulus; $b$ is the magnitude of Burger's vector. Equation (5) can be altered as

$\ln \left(\delta_{H} \varepsilon\right)=\ln C_{1}-\frac{C_{2}}{\varepsilon}$

The relationship between the damping capacity $(\delta)$ and the loss tangent $(\tan \varphi)$ can be expressed by the following equation

$\delta=\pi \tan \varphi, \quad(\tan \varphi<0.06)$

If the $\ln \left(\delta_{H} \varepsilon\right)-1 / \varepsilon$ plots ( $G-L$ plots) are straight lines, the intercept and slope are the values of $\ln C_{1}$ and $-C_{2}$, respectively. The $G-L$ plots of FAC/AZ91D composites under different processing conditions at high strain amplitude are shown in Fig. 10. The values of the parameters obtained from the $G-L$ plots are shown in Table 2. It can be observed that all the $G-L$ plots (Fig. 10) of different composites are almost straight lines, indicating that the dominant damping mechanism of FAC/AZ91D composites after isothermal heat treatment at different temperatures for $40 \mathrm{~min}$ is dislocation damping at high strain amplitude. In addition, it can be seen from Eq. (6) that the value of $C_{1}$ is directly proportional to $L_{\mathrm{N}}^{3}, \rho$ and inversely proportional to $L_{\mathrm{d}}^{2}$. Isothermal heat treatment can change the distribution of strong pinning sites $\left(\beta-\mathrm{Mg}_{17} \mathrm{Al}_{12}\right.$ and $\left.\mathrm{Mg}_{2} \mathrm{Si}\right)$ and weak pinning points (solute atoms). The number of weak pinning points increases as more and more $\beta-\mathrm{Mg}_{17} \mathrm{Al}_{12}$ are dissolved in the matrix with the increase in isothermal temperature, resulting in the decrease in $L_{\mathrm{d}}$. The $\mathrm{Mg}_{2} \mathrm{Si}$ particles would grow up by Ostwald ripening mechanism in the composite with the increase in the isothermal temperature, resulting in a reduction in the number of $\mathrm{Mg}_{2} \mathrm{Si}$ particles and leading to the increase in $L_{\mathrm{N}}$. Thus, the $C_{1}$

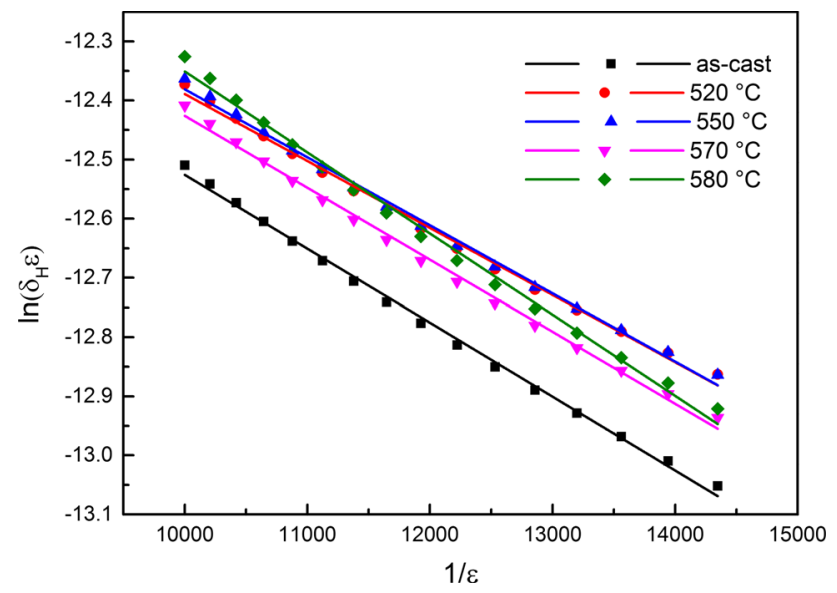

Fig. $10 G-L$ plots for FAC/AZ91D composites after isothermal heat treatment at different temperatures for $40 \mathrm{~min}$
Table 2 Values of parameters obtained from $G-L$ plots of FAC/ AZ91D composites after isothermal heat treatment at different temperatures

\begin{tabular}{lll}
\hline Temperature $\left({ }^{\circ} \mathrm{C}\right)$ & $C_{1}\left(\times 10^{-6}\right)$ & $C_{2}\left(\times 10^{-4}\right)$ \\
\hline As-cast & 12.6723 & 1.2497 \\
520 & 12.9321 & 1.1333 \\
550 & 13.2349 & 1.1506 \\
570 & 13.5510 & 1.2169 \\
580 & 17.0485 & 1.3713 \\
\hline
\end{tabular}

value of the composite after isothermal heat treatment at $580{ }^{\circ} \mathrm{C}$ is the largest. Therefore, the composite after isothermal heat treatment at $580{ }^{\circ} \mathrm{C}$ has a best damping capacity at high strain amplitude because of the large $C_{1}$ value and the nearly identical $C_{2}$ value.

It can be noted from Fig. 9 that the damping capacities of FAC/AZ91D composites increase with the increase in strain amplitude at low strain amplitude. However, the strain-independent damping $\delta_{0}$ is not found in Fig. 9, and the damping capacities increase quickly when the strain amplitude is small. This implies that other mechanisms different from the dislocation damping mechanism may also contribute to the damping capacities of FAC/AZ91D composites at room temperature. FAC may play an important role in improving the damping capacities of the composites. The interface damping is induced by the addition of the particles in the particle reinforced metal matrix composites and can be an important source of damping at room temperature [41]. As can be seen from Fig. 5, after the FAC were added into the AZ91D melt, the silica and alumina in FAC reacted with the magnesium, resulting in the formation of $\mathrm{Mg}_{2} \mathrm{Si}$ and $\mathrm{MgO}$. Meanwhile, some tiny holes appeared on the walls of FAC due to the reaction, and they were filled in magnesium alloy melt during the preparation process of the composite. After the solidification of the composite, the interfacial bonding strength of FAC and the matrix was weakened due to the large difference in thermal expansion coefficient between FAC and magnesium alloy matrix. In addition, the lattice constants of magnesium and phases in FAC differed greatly, and incoherent interface was formed between FAC and the matrix. As a result, the interface between FAC and the matrix was a weakly bound interface, and micro-slip occurred at low strain amplitude, resulting in the interface damping at the room temperature. Therefore, the strainindependent damping $\delta_{0}$ did not appear in the dampingstrain plots of FAC/AZ91D composites at low strain amplitude due to the interface damping. As can be seen from Fig. 6, many small magnesium particles formed inside $\alpha-\mathrm{Mg}$ grains after isothermal heat treatment, which 
are resulted from partial melting of the low-melting-point zone in the matrix. The interface bonding between the small alloy particles and the matrix is weak; thus, the interfacial slip would occur at low strain amplitude. Therefore, the existence of small alloy particles within the grains improves the damping capacities of FAC/AZ91D composites at low strain amplitude. The FAC/AZ91D composites after isothermal heat treatment at 520 and $550{ }^{\circ} \mathrm{C}$ have better damping capacities in the low strain region because there are many small alloy particles within the grains. Therefore, the dominant damping mechanism of FAC/AZ91D composites at low strain amplitude is interface damping, and the damping capacity increases rapidly as more interface slip with the increase in strain amplitude. Finally, the strain amplitude reaches a critical value when the increase in interface damping slows down, and dislocation damping becomes a major source of damping.

Figure 11 shows the temperature-dependent damping capacities of FAC/AZ91D composites after isothermal heat treatment at different temperatures for $40 \mathrm{~min}$. It can be noted that both the damping capacities of as-cast composite and heat-treated composites increase with the rise of the temperature, and the damping capacities of the composites after isothermal heat treatment are better than that of ascast composite. The difference in damping capacities of ascast composite and heat-treated composites is relatively small at test temperatures below about $225^{\circ} \mathrm{C}$, and the composite after isothermal heat treatment at $520^{\circ} \mathrm{C}$ has a better damping capacity. The damping capacities increase quickly at test temperatures above $225^{\circ} \mathrm{C}$, and the composites after isothermal heat treatment at high temperature possess better damping capacities.

As shown in Fig. 11, the damping capacities of the composites after isothermal heat treatment are better than that of the as-cast composite at test temperatures below

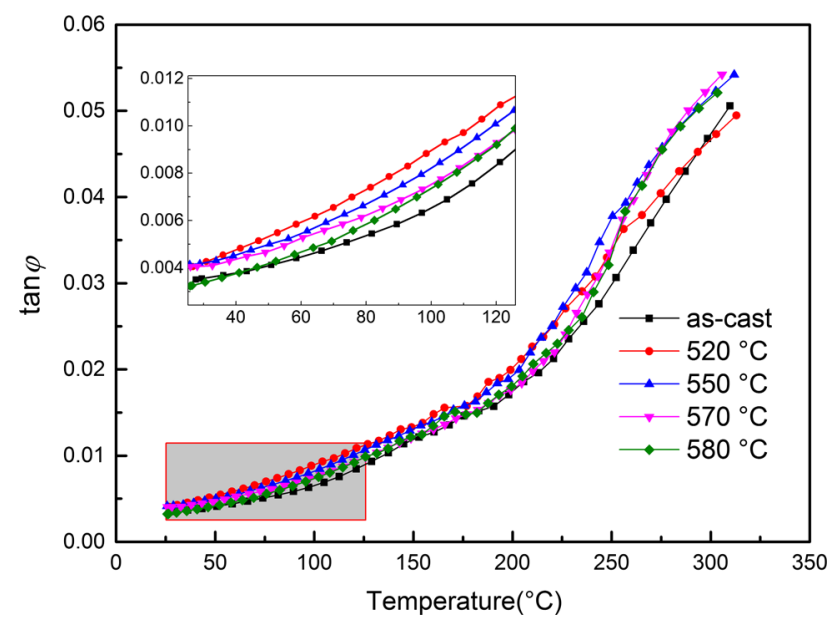

Fig. 11 Temperature-dependent damping capacities of FAC/AZ91D composites after heat treatment at different temperatures for $40 \mathrm{~min}$ about $100{ }^{\circ} \mathrm{C}$, and the increase rate of damping capacities of the composites after isothermal heat treatment is faster than that of the as-cast composite. This indicates that the small alloy particles resulting from isothermal heat treatment play an important role in improving the damping capacities of the composites at test temperatures below about $100{ }^{\circ} \mathrm{C}$. The damping capacities of the composites increase with the increase in the number of small alloy particles, and the composite after isothermal heat treatment at $520{ }^{\circ} \mathrm{C}$ has the best damping capacities. The damping mechanism of FAC/AZ91D composites is mainly interface damping when the test temperature is below about $100{ }^{\circ} \mathrm{C}$.

When the test temperature is greater than $100{ }^{\circ} \mathrm{C}$, the damping capacities of the composites at different states begin to increase rapidly. However, the difference in damping capacities of different composites becomes very small when the test temperature reaches $175^{\circ} \mathrm{C}$. In this temperature range, the dislocation mechanism can be considered to play a major role in improving the damping capacity. As the test temperature increases, the stress for dislocation break-away from weak pinning points decreases because the process is thermally activated [42]. The dislocation damping of the composite after isothermal heat treatment at $580{ }^{\circ} \mathrm{C}$ is the best. Therefore, the difference in damping capacities of different composites decreases gradually as the test temperature increases from 100 to $175^{\circ} \mathrm{C}$.

As can be seen from Fig. 11, the damping capacities of all the composites increase more rapidly when the test temperature is higher than $175^{\circ} \mathrm{C}$. Meanwhile, the damping capacities of the composites after isothermal heat treatment at 570 and $580{ }^{\circ} \mathrm{C}$ increase quickly and have better damping performance at high test temperatures. Grain boundary damping is very sensitive to the test temperature, and the viscous slip at grain boundaries converts the strain energy into other energy [43]. Therefore, the grain boundary damping is the main source of damping capacity at high test temperatures. As can be seen from Fig. $5, \beta-\mathrm{Mg}_{17} \mathrm{Al}_{12}$ phase is distributed between the $\alpha-\mathrm{Mg}$ dendrites for the as-cast composite, which hinders grain boundary slip, resulting in lower grain boundary damping for the as-cast composite. After isothermal heat treatment at $520{ }^{\circ} \mathrm{C}$ for $40 \mathrm{~min}$, the $\alpha-\mathrm{Mg}$ grains in the composite are still dominated by dendrites. The alloy particles formed at grain boundaries make the grain boundary slip difficult, and thus, the composite still has lower grain boundary damping after isothermal heat treatment at $520{ }^{\circ} \mathrm{C}$. Therefore, the as-cast composite and the composite after isothermal heat treatment at $520{ }^{\circ} \mathrm{C}$ have lower damping capacities at high test temperatures. With the increase in isothermal temperature, polygonal or nearly spherical $\alpha$ $\mathrm{Mg}$ grains are formed. It is easy for grain boundaries to slip at high test temperatures, leading to better damping 
capacities for the composites with isothermal temperature higher than $550{ }^{\circ} \mathrm{C}$.

\section{Conclusions}

1. The FAC/AZ91D composites were prepared successfully by stir casting method, and isothermally heattreated at different temperatures for different time. With the increase in isothermal temperature or holding time, the small liquid droplets within grains increase in size but decrease in quantity. The average size and shape factor of $\mathrm{Mg}_{2} \mathrm{Si}$ particles increase with the rise of isothermal temperature.

2. The microstructural evolution during isothermal heat treatment can be divided into five steps, initial coarsening of the $\alpha-\mathrm{Mg}$ dendrites, structural separation, coarsening of polygonal $\alpha-\mathrm{Mg}$ grains, spheroidization of polygonal solid grains and final coarsening.

3. At room temperature, the damping capacities of $\mathrm{FAC} /$ AZ91D composites increase with the increase in strain amplitude, and the isothermal heat treatment improves the damping capacities of the composites. The composites after heat treatment at 520 and $550{ }^{\circ} \mathrm{C}$ have a higher damping capacity due to interface damping when the strain amplitude is lower than about $8.8 \times 10^{-5}$, and the composite after heat treatment at $580{ }^{\circ} \mathrm{C}$ has a better damping capacity because of the dislocation damping when the strain amplitude is high.

4. The damping capacities of FAC/AZ91D composites increase with the rise of test temperature, and the isothermal heat treatment improves the damping capacities of composites at different test temperatures. The interface damping plays an important role when the test temperature is below about $100{ }^{\circ} \mathrm{C}$, and the dislocation damping and grain boundary damping take effect when the test temperature rises.

Acknowledgements This work was supported by the Open Fund (No. OGE201702-07) of Key Laboratory of Oil and Gas Equipment, Ministry of Education (Southwest Petroleum University), the Key Research and Development Project of Shandong Province (No. 2016GGX102041), the Natural Science Foundation of Shandong Province (No. ZR2017LEM004) and the Fundamental Research Funds for the Central Universities of China (No. 18CX02091A).

\section{References}

[1] W. Jiang, G. Li, Z. Fan, L. Wang, F. Liu, Metall. Mater. Trans. A 47, 2462 (2016)

[2] W.J. Joost, P.E. Krajewski, Scr. Mater. 128, 107 (2017)

[3] W. Jiang, Z. Fan, G. Li, L. Yang, X. Liu, Metall. Mater. Trans. A 47, 6487 (2016)
[4] Q. Yuan, X. Zeng, Y. Wang, L. Luo, Y. Ding, D. Li, Y. Liu, J. Mater. Sci. Technol. 33, 452 (2017)

[5] L. Chen, Y. Yao, Acta Metall. Sin. (Engl. Lett.) 27, 762 (2014)

[6] A. González, R. Navia, N. Moreno, Waste Manag. Res. 27, 976 (2009)

[7] R. Wasserman, A. Bentur, Cem. Concr. Res. 27, 525 (1997)

[8] L.C. Ram, R.E. Masto, Earth-Sci. Rev. 128, 52 (2014)

[9] A. Zhang, N. Wang, J. Zhou, P. Jiang, G. Liu, J. Hazard. Mater. 201, 68 (2012)

[10] M. Sarmah, B.P. Baruah, P. Khare, Fuel Process. Technol. 106, 490 (2013)

[11] F.A. Torralvo, C. Fernández-Pereira, Miner. Eng. 24, 35 (2011)

[12] J. Liu, Y. Dong, X. Dong, S. Hampshire, L. Zhu, Z. Zhu, L. Li, J. Eur. Ceram. Soc. 36, 1059 (2016)

[13] T. Matsunaga, J.K. Kim, S. Hardcastle, P.K. Rohatgi, Mater. Sci. Eng. A 325, 333 (2002)

[14] J.D.R. Selvam, D.S.R. Smart, I. Dinaharan, Mater. Des. 49, 28 (2013)

[15] M. Hrairi, M. Ahmed, Y. Nimir, Adv. Powder Technol. 20, 548 (2009)

[16] S. Sankaranarayanan, Q.B. Nguyen, R. Shabadi, A.H. Almajid, M. Gupta, Powder Metall. 59, 188 (2016)

[17] P.K. Rohatgi, A. Daoud, B.F. Schultz, T. Puri, Compos. Part A Appl. Sci. Manuf. 40, 883 (2009)

[18] N.N. Lu, X.J. Wang, L.L. Meng, C. Ding, W.Q. Liu, H.L. Shi, X.S. Hu, K. Wu, J. Alloys Compd. 650, 871 (2015)

[19] S.R. Yu, Z.Q. Huang, J. Mater. Eng. Perform. 23, 3480 (2014)

[20] Q.B. Nguyen, M.L.S. Nai, A.S. Nguyen, S. Seetharaman, E.W.W. Leong, M. Gupta, Mater. Sci. Technol. 32, 923 (2016)

[21] W. Huang, H. Luo, H. Lin, Y. Mu, B. Ye, J. Mater. Eng. Perform. 25, 587 (2016)

[22] Y.W. Wu, K. Wu, K.K. Deng, K.B. Nie, X.J. Wang, M.Y. Zheng, X.S. Hu, Mater. Des. 31, 4862 (2010)

[23] G. Parande, V. Manakari, G.K. Meenashisundaram, M. Gupta, Int. J. Mater. Res. 107, 1091 (2016)

[24] J.H. Jun, Mater. Trans. 53, 2064 (2012)

[25] W. Cao, C. Zhang, T. Fan, D. Zhang, Mater. Sci. Eng. A 496, $242(2008)$

[26] X. Zhang, L. Liao, N. Ma, H. Wang, Mater. Lett. 60, 600 (2006)

[27] M.C. Flemings, Metall. Trans. A 22, 957 (1991)

[28] X. Wu, F. Han, W.W. Wang, Trans. Nonferrous Met. Soc. China 19, s331 (2009)

[29] T.J. Chen, X.D. Jiang, Y. Ma, Y.D. Li, Y. Hao, J. Alloys Compd. 505, 476 (2010)

[30] M. Yang, F. Pan, R. Cheng, L. Bai, J. Mater. Process. Technol. 206, 374 (2008)

[31] D. Yao, Y. Zhang, Mater. Lett. 166, 201 (2016)

[32] R.S. Blissett, N.A. Rowson, Fuel 97, 1 (2012)

[33] P.K. Rohatgi, J.K. Kim, N. Gupta, S. Alaraj, A. Daoud, Compos. Part A Appl. Sci. Manuf. 37, 430 (2006)

[34] Z. Huang, S. Yu, J. Alloys Compd. 509, 311 (2011)

[35] G.R. Ma, X.L. Li, L. Xiao, Q.F. Li, J. Alloys Compd. 496, 577 (2010)

[36] E. Liu, S. Yu, Y. Zhao, F. Li, S. Zhang, J. Li, M. Yuan, Rare Metal Mater. Eng. 46, 3298 (2017). (in Chinese)

[37] T.J. Chen, X.D. Jiang, Y. Ma, Y.D. Li, Y. Hao, J. Alloys Compd. 497, 147 (2010)

[38] A. Granato, K. Lücke, J. Appl. Phys. 27, 789 (1956)

[39] A. Granato, K. Lücke, J. Appl. Phys. 27, 583 (1956)

[40] W. Huang, H. Zhan, L. Xu, Z. Xu, J. Zeng, Acta Metall. Sin. (Engl. Lett.) 22, 211 (2009)

[41] Y. Zhang, N. Ma, H. Wang, Mater. Lett. 61, 3273 (2017)

[42] A.V. Granato, K. Lücke, J. Appl. Phys. 52, 7136 (1981)

[43] K.F. Tam, S.C. Tjong, Mater. Sci. Technol. 20, 1055 (2004) 